\title{
Systematic Observation of Children with Pervasive
}

\section{Developmental Disorders}

\author{
Christine K. Syriopoulou- Delli \\ Teaching Assist \\ Department of Educational and Social Policy, University of Macedonia \\ 156 Egnatias st. 54006 Thessaloniki, Greece \\ Tel: 30-210-698-3603 E-mail: dellis@mfa.gr
}

Received: November 7, $2010 \quad$ Accepted: December 23, $2010 \quad$ doi:10.5539/res.v3n1p54

\begin{abstract}
Observation is considered a reliable method for the recognition of behavioural, communicative, cognitive, sensory and motor difficulties. However, the assessment of children with pervasive developmental disorders (PDD) should not be confined to the application of one method (Kroustalakis 1994, Polychronopoulou 1995, Vosniadou, 1995). This article aims to present the method of systematic observation (value, aim, techniques and the role of observer), as well as to propose other techniques of assessment and diagnosis for children with PDD. The conclusion is that since PDD characteristics change during a child's development and they vary among individuals, since diagnostic criteria and tools have not yet been commonly decided among professionals, causes of PDD are still under investigation and treatments have not been defined, systematic observation can contribute to the assessment of children with PDD and make the environment functional to child's needs.
\end{abstract}

Keywords: Systematic observation, Pervasive developmental disorders, Techniques, The observer, Assessment

\section{The origins of systematic observation}

The scientific study of child development started in the middle of the $18^{\text {th }}$ century, an era characterized by an increase in scientific research and especially the development of biology, which posed new questions regarding the developmental process of organisms. According to Jean Jacques Rousseau, childhood has its own position in the human development and consequently we should judge the behaviour of a child with different criteria to that which we judge the behaviour of an adult. Respect towards childhood and the individuality of each child and generally respect towards a distinguished, liberal and democratic discipline springs from this perception. This perception was continued by Werner in USA and Piaget in Europe, the result was the beginnings of systematic observation and research in relation to the motor, sensory, cognitive, emotional and social development of children (Haralampopoulos, 1993). The Industrial Revolution gave a great boost to the progress of developmental psychology as a science. A complex world was formulated that demanded the education of a great number of people, they needed learn to read, write and use complex machines. The systematic study of child development and learning ability became necessary with the widening of access to schools, to include a larger number of people than ever before, and an increase in the educational material to be assimilated. Questions such as: what is a child and how does it develop? began to occupy human thought after $17^{\text {th }}$ century and resulted the appearance of scientific theories related to the nature of childhood and how it develops. Charles Darwin and G. Stanley Hall were the first to deal with change in children and youths. The former donated funds for the development of species. He saw the child as a rich source of scientific information which could be used for the comprehension of adult behaviour. The latter used scientific tools (questionnaire) for first time in the study of human behaviour in large populations. Systematic observation was the first method used for the study of child development. At the end of the $18^{\text {th }}$ century, medical doctors, teachers, psychologists and parents kept diaries of their children's development, where they described in detail changes in corporal, emotional and cognitive development. Darwin presented a biography of his son (Darwin, 1877).

The systematic observation of individual cases of children was replaced by the systematic observation of large number of children in research aiming to create models of development that defined the "typical" or "normal" behaviour of a child at different ages (Gessell, Thompson, Amatruda, 1929). Later psychologists turned to 
experimental studies that allowed the examination of particular arguments for the causes of behaviour. The Swiss psychologist Jean Piaget (1963) based his theory of the development of intelligence during infancy on the observation of his three children.

The method of systematic observation has been used by sociologists, ethnologists and other researchers as an ethno-methodological research approach (Burgess, 1984). In special education it is used by teachers, parents, counsellors as well as by medical doctors and other specialists involved in the development and education of children.

Systematic observation can be based on: a) linguistic development (echolalia, communication, structure, meanings, comprehension, verbal and non-verbal characteristics of communication), b) social relations, emotional development (interaction with people of the environment, development of relations) c) (gross or fine) motor development (tic, nervous or repetitive movements), d) sensory development (sensitivity to sounds) and e) cognitive development (perception, memory, imagination).

\section{The Value of Observation}

The collected data is considered reliable because systematic observation is applied on a child's natural environment, in places where the child lives and gets education. It might last long term or be repeated periodically, contrary to standardized psychological tests, for example, that are implemented once only under psychological laboratory conditions.

Systematic observation might contribute to the improvement of relations between parents and teachers and other specialists (e.g. medical doctors). This happens because when teachers or medical doctors have information on a child, they then seek to convey this information to parents. They are interested in collecting data from parents on the child's behaviour at home, in order to compare it with that which they themselves have observed. Information (from medical doctors and other specialists) on a child's behaviour contribute to an increase in teachers' self-esteem and confidence. Through observation a more global impression about a particular child is gained and changes are identified. Sometimes observation encourages parents to observe a child's progress and adaptability and may lead them to diminish demands on their children. Systematic observation leads to the avoidance of pointless, failed strategies of assessment and to the reformation of treatment approaches and consequently to savings in effort and time. Also, it helps the demystification of the syndromes' characteristics and makes the direct environment more communicative. This contributes to improvements in the familial, social and educational integration of the child, regarding relations with people in the environment, parental adaptation and child guidance.

Systematic observation implemented in children with pervasive developmental disorders is beneficial because disorders develop in a spectrum which has a variety of different characteristics that are different both in nature and degree from child to child and at each age or developmental stage. The causes of the autistic syndrome or other PDD remain unknown and research on them continues, making their confrontation an individual process. Specialists have not reached a common agreement on PDD characteristics that should be used as criteria. However, a number of symptoms might appear simultaneously in a child. Therapies remain undefined and individualized. Protocol regarding the communication of a child with PDD with its environment remains particular and the interaction with it may be verbal or non-verbal.

\section{Aim}

The aim of systematic observation is not only the recording of what a child does, but also how it does it, information that characterizes the quality of an activity and differentiates it from others. The definition of developmental stage is based upon these elements. By understanding a child with PDD, its possibilities and needs, the definition of its individual characteristics is possible. Systematic observation reduces the danger of "labeling". The assessment of a child should be carried out with particular sensitivity, paying careful attention to fine quality divergence, as well as to difficulties in learning and social activities. In addition there is the decoding and definition of the individual protocol of communication, in order a supportive environment and an educational program to be organized, aiming to the cultivation of behaviours and skills. Systematic observation contributes to the application of individual strategies of intervention whenever this is necessary and to the formation of work-groups. Infrastructure and teaching material can be arranged in order to become more functional. It gives information on the process of translating environmental stimulus from a child (cognitive, sensory or other elaboration). Systematic recording is a way to realize the permanent stimuli of behaviour which appear systematically and the changing motives of behaviour that appear occasionally. Behaviours that have been recognized as unwanted or inappropriate are confronted and restricted while wanted behaviours are encouraged. The possibility of controlling the start of activities is available. By defining the scale of individual 
ability of a child, parents and/or teachers make decisions on how to intervene in individual and group activities (for example play). They can combine the amount and nature of support over the period of development of the child, namely when parental or teacher support should stop and when the child should undertake initiative for action on its own (Tjouriadou, 1995). It contributes to facilitating the expression of a child and the satisfaction of their needs in each developmental stage. In addition, systematic observation contributes to the security of children with PDD and the approach taken in situations such as illness, self-injury and so on. Also, it contributes to the recording and assessment of symptoms as well as the possible definition of causes. Cooperation is facilitated amongst family, school and other members involved in the educational and vocational integration of the child.

\section{Techniques}

Techniques for the implementation of systematic observation include:

- Involvement of an adult in pre-defined activities over a defined period of time (direct trial, structured activities).

- Participation of an adult as an external observer who does not participate in children's activities.

- Systematic observation during particular activity over a defined time span (Polychronopoulou, 1995).

- Occasional systematic recording of behaviour whenever the observer is able to keep quick notes.

- Recording of behaviour in defined activities with a cognitive, social content or in motor activities or in reactions to sensor stimulus.

- Organization of an individual file of work where progress is recorded.

- Use of tests such as: a) the test of play preference. This is a tool of observation of a whole play team. The test includes: each child's preferred material for play, the interaction with objects, the topics of play and the fellow-players. The information recorded helps in the recognition of models of play and interests that different members of a team share. b) The profile of characteristics of individual play (Fenson \& Schell, 1986; McCune-Nicholich, 1981; Piaget 1962; Smilansky, 1968; Quill, 1995), which is an observation tool for the recording of apparent behaviours and preferences of a new member in play. It includes the definition and description of symbolic dimensions of play, the social dimensions of play and the communicative strategies, as well as the preferred activities of play, the material and the fellow players.

- Non-participation of the observer. The observer may only give stimulus to guide the activity but not directly participate in its implementation.

- Change in the role of observer during systematic observation, namely the observer is at times the coordinator of the team or the activity and at other times part of the team and joins in the activities with the children.

Observation can be supported by a tape-recorder in order the elaboration of the material is possible with the cooperation of parents and the presence of the child at a later moment. Assessment of a child's behaviour is feasible by specialists and inter-scientific assessment is facilitated as well as the organization of intervention methods. In addition, the use of video serves to enable debate between specialists and family members on topics related to the behaviour of their child or other children's behaviour. Progress or regression may be recorded over a particular period; also adults might convey material to specialists regarding the reaction of the child during the period that the child is at home. In this way the targets of intervention are assessed and when it is necessary they are revised and redesigned. The use of a child's photos in every day situations contributes to the transfer of information and the cooperation of specialist staff and family members. Observation might be individual in a spontaneous or directed activity or it can be group focused or it might concern the observation of a child when it interacts with another person (child or adult) or team. Observation can be done whilst the child is occupied with a specific material (colours, cubes and so on) that a teacher, therapist or other person has given to the child. Also, observation and recording is implemented during the child's interaction with people in its environment (such as adults and the peers), as well as for the assessment of skills of self-service (feeding, dressing, cleaning, personal care, sleeping, toilet duties and so on) (Vosniadou, 1995).

\section{The observer}

The person dealing with recording the information from systematic observation should give particular attention to the selection of words which describe a child's actions with accuracy. The observer should not be influenced by sentiment or reflect personal preoccupations or social and cultural values. Recording includes every detail of the stimulus, the setting and the child's reaction. The person who records can combine information with other techniques (like interview with parents). 
Observation can be implemented by the members of the family, such as parents. They belong to the child's direct social environment from the first moment of its life and spend many hours with the child. These people carry the greatest burden of responsibility for the recognition of difficulties at an early age and for the seeking of support through early intervention programs. Parents, is important to be informed by specialists on PDD as to the child's development and the techniques of systematic observation so that they may cooperate with therapists.

In addition, systematic observation and recording can be implemented by the teacher while the child is in the classroom, in the school playground, during school events or during events outside the school. A teacher knows better than anyone else the exact difficulties of a child in specific subjects and the particular demands of the school community. A teacher is aware of the way in which a child learns, its interests and which activities it avoids or is unable to do. Teachers can not carry out diagnosis, however, they can provide information to parents and special staff and they can also organize the physical and social environment as well as the program of intervention.

Additionally, medical doctors can implement techniques of observation during an examination visit to a child; they can diagnose and construct a therapeutic approach. They have a variety of techniques available, such as magnetic representation of the brain, chromosome analysis, hormonal analysis and metabolic examination, with which they can cross-check their assumptions through observation. Both the counsellor and the psychologist may apply techniques of observation during the implementation of home-programs or during child's visits to their office, in addition they may use standardized tests, screening tests and so on.

\section{Other diagnostic tools}

The two most accepted systems of diagnosis in relation to the diagnostic criteria of pervasive developmental disorders are: the Diagnostic and Statistic Manual of Mental Disorders, $4^{\text {th }}$ edition (DSM-IV 1994), by the American Psychiatric Association and the International Categorization of Diseases, $10^{\text {th }}$ edition (ICD-10, 1993) by the International Organization of Health. These have been compiled after many years of trialing. The creation of a diagnostic system, which is relatively reliable, became possible based on empirical trial and the abandonment of inaccurate characteristics and conclusions for the causes. A common language for diagnosis tends to be available and to contribute to the communication amongst those dealing with the research and confrontation of this population.

An important first assessment of the classification system is the ability not only to identify people that should be included in the diagnostic category, but also to define who should be excluded from the category. In other words it is important that the diagnostic tool is able to make a distinction between the disorders which are very similar and share common characteristics. DSM-IV separates autistic disorders and other forms of pervasive developmental disorders, namely Rett syndrome, Asperger syndrome, childhood disintegrative disorder and PDD-not otherwise specified.

A series of diagnostic tools supported by empirical research findings have been created. These include the Denver Developmental Screening Test (D.D.S.T.). This tool investigates mental insufficiency and psychological and motor development in preschool age children (from 1 month to 6 years). It includes 105 trials/skills which are constructed in a developmental way, (namely abilities according the age). Skills are separated into four sectors: a) Gross motor skills (walking, balance, jump, and ability to sit). b) Fine motor skills and perception (visual-motor coordination, painting, copy of shapes). c) Language-speech skills (auditory, speech, vocabulary, comprehension of meanings, realization of commands). d) Sociability skills (ability of self-service, cooperation with others). This scale is applied by a trained person and are of a short-term duration therefore are applied to the assessment of large populations (Frankenburg \& Dodds, 1967).

Another tool for child assessment is the Autism Diagnostic Interview Revised ADI-R and the Autism Diagnosis Observation Scale Generic (ADOS-G). ADI-R is a detailed interview which is coordinated by a trained person. The child and a parent participate too. Detailed information is collected on the child's development in relation to the basic behaviours for autism (such as social attachment, social behaviour, communication, stereotypes). The interview lasts for two hours and is usually completed using the ADOS-G and conducted by an educated person who works with the child under predefined conditions of interaction which are designed to confine the characteristics of autistic behaviours. For example, the person tries to make the child participate in a variety of activities such as: imitating activities, concentration of attention, pretend play and several verbal behaviours. ADI-R and ADOS-G collect information from different sources (such as the parent, the observer) in a systematic way. It assesses areas included in the DSM-IV and ICD-10.

A Check-list for early investigation is Checklist for Autism in Toddlers (M-CHAT) for children from 18 to 36 months. It consists of two parts. The first part includes a questionnaires for parents with 23 questions on 
behaviours that the child shows persistently and for long periods (for example during play, the child climbs or pretends to be chatting on the phone), not just occasionally. Questions are answered with a YES or NO. Some questions are considered particularly critical in assessment. The second part includes a questionnaire with 9 questions and instructions that are filled in by the pediatrician (Robins, Fein, Barton \& Green, 1991). The pediatrician observes the child during the visit to the office and collects information from parents. Questions are answered with a YES or NO. This list has been designed to detect likely pervasive developmental disorders. Parents who are aware about their child should then cross check information collected using M-CHAT with other diagnostic tools.

Doll's Vineland Social Maturity Scale (Sparrow, Balla \& Cicchetti, 1984), the modern name is Vineland Adaptive Behavior Scale, is used for the assessment of adaptive behaviour. It includes 117 issues grouped into levels according to age. Information is collected from individual interviews with the child itself or the parents. The issues concern activities that the child could implement in every day life and they are separated into eight categories: general self-help, self-help during meals, self-help in dressing, self-service, occupation, communication, mobility and socialization.

Childhood Autism Rating Scale (CARS) (Schopler, Reichler, \& Renner, 1988) developed through the TEACCH program in North Carolina and it concerns the observation of the behaviour of children aged 0-12 years old.

\section{Conclusion}

The appearance of different characteristics of PDD during a child's developmental stages, the continuous consideration and investigation of criteria of assessment and of diagnostic tools by professionals, the non identification of causes and the non definition of treatments, constitute systematic observation a method of assessment that can lead to comprehension of an autistic child's behaviour and needs, make social environment functional and intervention approaches effective.

\section{References}

American Psychiatric Association. (1994). Diagnostic and Statistical Manual of Mental Disorders, $4^{\text {th }}$ ed.. Washington, DC.

Bender, L. (1947). Childhood Schizophrenia: Clinical Study of One Hundred Schizophrenic Children. American Journal of Orthopsychiatry, 17: 40-56.

Bleuler, E. (1950). Dementia Praecox or the Group of Schizophrenias, trans. Zinkin, J.. New York: International Universities Press.

Burgess, R. (1984). Research Methodology in Education. London: Press Plc.

Chawarska, K., Klin, A., Paul, R. \& Volkmar, F. (2007). Autism spectrum disorder in the second year: stability and change in syndrome expression. Journal of child psychology and psychiatry and allied disciplines, 48(2): $128-38$.

Constantino, J. N., Lavesser, P. D., Zhang, Y., Abbacchi A. M., Gray, T. \& Todd, R. D. (2007). Rapid quantitative assessment of autistic social impairment by classroom teachers. Journal of the American Academy of Child and Adolescent Psychiatry, 46(12): 1668-76.

Croen, L. A., Grether, J.K., Hoogstrate \& Selvin, S. (2002). The Changing Prevalence of Autism in California. Journal of Autism and Developmental Disorders, 32: 207-215.

Darwin, C. (1877). A Biographical Sketch of an Infant. Mind, 2: 284-294.

Dawson, G. (1991). A psychological perspective on the socio-emotional development of children with autism, ed. Cicchetti, D., Toth, S. 3: pp.207-34. Rochester NY: University of Rochester Press.

Frith, U. (1989). Autism. Oxford: Blackwell.

Fombonne, E. (2003). Epidemiological Surveys of Autism and Other Pervasive Developmental Disorders: An Update. Journal of Autism and Developmental Disorders, 33: 365-382.

Frankenburg, W. K. \& Dodds, J. B. (1967). Denver Developmental Screening Test D.D.S.T.

Gessell, A., Thompson, H. \& Amatruda, C. S. (1929). The Psychology of Early Growth Including Norms of Infant Behaviour and Method of Genetic Analysis. New York: MacMillan.

Haralampopoulos, V. (1993). Personality Development. Athens: Gutenberg Plc (in Greek). 
Hepburn, S. L., Guiseppi, C., Rosenberg, S., Kaparich, K., Robinson, C. \& Miller, L. (2008). Use of teacher nomination strategy to screen for autism spectrum disorders in general education classrooms: a pilot study. Journal of Autism and Developmental Disorders, 38 (2): 373-82.

Ingram, D. H., Mayes, S. D., Troxtell, L. B. \& Calhoun, S. L. (2007). Assessing Children with autism, mental retardation and typical development using the Playground Observation Checklist Autism. The International Journal of Research and Practice, 11(4): 311-9.

Kanner, L. (1943). Autistic Disturbances of Affective Contact. Nervous Child, 2: 217-250.

Kroustalakis, G. (1994). Children with special needs. Athens (in Greek).

Lennard-Brown., S. (2004). Autism trans. Nikolakaki Athens: Savalas Plc (in Greek) from Lennard-Brown, S. (2003). Autism. London: White-Thomson Plc Ltd.

Lerman, D, Tetreault, A., Hovanetz, A., Strobel, M. \& Garro, J. (2008). Further Evaluation of a Brief, Intensive Teacher-Training Model. Journal of Applied Behaviour Analysis, 41 (2): 243-248.

Mahler, M. (1952). On Child Psychosis and Schizophrenia, Autistic and Symbiotic Infantile Psychoses. Psychoanalytic study of the Child, 7: 286-305.

Piaget, J. (1963). The Origins of Intelligence in Children. New York: Norton.

Polychronopoulou, S. (1995). Children and Youth with special needs and abilities. Athens (in Greek).

Porpodas, K. (1993). Cognitive Psychology, Issues on Language Psychology, Problem Solving, Vol. 2. Athens (in Greek).

Quill, K. A. (1995). Teaching Autistic Children. Ways to increase communication and sociability. Athens: ELLIN Plc (in Greek).

Robins, D. L., Fein, D., Barton, M. \& Green, J. A. (2001). Modified Checklist for Autism in Toddlers (M-CHAT). Journal of Autism and Developmental Disorders, 31(2): 145-148.

Rutter, M. (1987). Infant Autism trans Karandanos. Athens: Ellinika Grammata (in Greek).

Schopler, E. Reichler, R. \& Renner, B.R. (1988). The Childhood Autism Rating Scale. Los Angeles: Western Psychological Services.

Schreibman, L. (2005). The Science and Fiction of Autism. USA: Harvard University Press.

Sparrow, S. S., Balla, D. A. \& Cicchetti, D. V. (1984). Vineland Adaptive Behaviour Scales. Interview Edition. Survey from manual, USA: Circle Pines, MN: American Guidance Service.

Tjouriadou, M. (1995). Children with special educational needs. Thessaloniki: Promitheas Plc. (in Greek).

Tsikoulas, I. (1983). Study of psychomotor developmenl of Greek children from infancy to school age with the application of the Denver Developmental Screening test (D.D.S.T.). Standardization of D.D.S.T in Greece. Thessaloniki (in Greek).

Vosniadou, S. (1995). trans Observing and Recording Children's Behaviour. Athens: Gutenberg Plc. from Cohen, D., Stern, V, Balaban, N. (1983). Observing and Recording the Behaviour of young children. Teachers College Press \& Columbia University Press.

Wing, L. \& Could, J. (1979). Severe Impairments of Social Interaction and Associated Abnormalities in Children: Epidemiology and Classification. Journal of Autism and Developmental Disorders, 9: 11-29. 